\title{
THE INFLUENCE OF THE THYROID ON ADRENAL CORTICAL FUNCTION
}

\author{
By RALPH E. PETERSON
}

(From the National Institute of Arthritis and Metabolic Diseases, National Institutes of Health, Bethesda, Md.)

(Submitted for publication October 29, 1957; accepted December 17, 1957)

The evidence is quite conclusive from animal studies that an excess of circulating thyroid hormone results in adrenal enlargement, and hypothyroidism produced by surgical thyroidectomy or by administration of antithyroid drugs results in adrenal atrophy. This subject has been extensively reviewed by Money (1). Studies of adrenal size in patients with thyroid disease coming to autopsy have yielded conflicting reports. Means (2) reported no change in adrenal size in hyperthyroidism, Marine (3) and LeCompte (4) reported a decrease in size of the adrenal, and Holst (5) found enlarged adrenals in some patients with hyperthyroidism. Berkheiser (6) reported an advanced case of hypothyroidism, with atrophy of the adrenals and lipoid depletion.

Measurements of adrenal size may not, however, always represent a completely satisfactory "yardstick" for evaluation of adrenal cortical secretory activity $(7,8)$. In the past few years, several investigators have reported measurements of various plasma and urinary steroid fractions in hyper- and hypothyroidism in man. Several investigators have reported on the levels of free urinary corticoids (9-12) in hyperthyroidism, and in myxedema $(9,10)$. Because of the relatively nonspecific methods of assay used these data are difficult to interpret. Urinary 17-ketosteroids have usually been found to be low in both hyperand hypothyroidism (9-18). Plasma 17,21-dihydroxy-20-ketosteroids have been reported to be normal in these diseases (19-21). Guinea pigs, which excrete a large fraction of the cortisol metabolites as free 17,21-dihydroxy-20-ketosteroids, show an increased excretion of free urinary corticoids after administration of thyroxine (20). In patients with clinical myxedema, the urinary level of the total free and glucuronide conjugated 17,21dihydroxy-20-keteosteroids has been found to be decreased, whereas in hyperthyroidism the level of these urinary steroids is either normal or slightly increased (20).

Thyroidectomized rats (22) and cats (23) are reported to survive adrenalectomy better than animals with an intact thyroid, and administration of thyroid to the adrenalectomized cats produced sudden death of the animals. Also, in patients with Addison's disease, acute adrenal cortical failure may be precipitated if thyroid hormone is administered $(24,25)$. Primary myxedema has been observed in which the presenting findings were those of adrenal cortical insufficiency, and adrenal function returned to normal following thyroid hormone therapy (26).

With the advent of new and improved methods for the measurement of certain of the adrenal cortical hormones, and the availability of cortisol4-C ${ }^{14}$, it has become possible to further study the relationship of the thyroid hormone to adrenal cortical function. These techniques have been applied to a study of the rate of degradation and the rate of synthesis of cortisol in myxedema and thyrotoxicosis, before and after therapy. In this manner, much new information has been gained regarding the state of activity of the adrenal cortex in these diseases.

\section{MATERIALS AND METHODS}

Eight patients with the classical symptoms, signs, and laboratory findings of thyrotoxicosis (Grave's disease) and seven patients with findings typical of primary myxedema ${ }^{1}$ served as the subjects of these studies. All the patients had hypo- or hyperthyroidism of moderate severity. Diagnoses were established on the basis of the

1 The diagnosis of hypopituitarism would appear to have been ruled out on the basis of the following: 1) normal plasma cortisol levels, 2) return of the urine corticosteroid levels (A. A., M. H., G. B.) and cortisol turnover rates (M. H., H. A., A. A., G. B.) to normal following treatment with dessicated thyroid, and 3) normal adrenal response to corticotropin in Patients W. C. and M. L. 
clinical picture, basal metabolic rate, thyroid uptake of $\mathrm{I}^{131}$, serum cholesterol, and serum protein-bound iodine. One normal subject was studied prior to and during the four week period following the administration of triiodothyronine ( $300 \mu \mathrm{g}$. per day) to induce a hyperthyroid state.

Plasma cortisol and urinary corticosteroids were determined by the modified $(27,28)$ procedure of Silber and Porter (29). Urinary 17-ketosteroids were determined by the Zimmermann procedure modified from the Holtorff and Koch method (30).

The steroids for intravenous administration were dissolved in ethanol and diluted to 300 or $500 \mathrm{ml}$. with 5 per cent dextrose in water to a final alcohol concentration of approximately 5 per cent. Following rapid infusion of the steroids, plasma samples were collected and assayed. The rate of disappearance of the steroids was expressed as a biologic half-time. Cortisol was assayed by the modified Silber-Porter procedure. The specificity of this assay procedure for cortisol in plasma following infusion of cortisol has been evaluated by isotope dilution (28) and found to be good. Cortisone and corticosterone were assayed by an isotope dilution method, since the phenylhydrazine assay for cortisone (31), and, to a lesser extent, the fluorometric assay for corticosterone (32), were not found to be specific for the determination of these steroids in plasma following their infusion. Urine cortisol concentration following the infusion of cortisol was also determined by the isotope dilution procedure.

The rapidly exchangeable miscible pool of cortisol and the rate of turnover of the pool 2 were determined by the previously described method (33). Two hundred to $300 \mu \mathrm{g}$. of cortisol-4-C ${ }^{14}$ (10 to 20 per cent of the pool size) were injected over a two to three minute period at 9:00 a.m. Plasma samples were collected every $30 \mathrm{~min}$ utes for the next three hours for measurement of the specific activity of cortisol.

\section{RESULTS}

Table I lists the plasma cortisol and urinary corticosteroid and 17-ketosteroid levels in the patients studied. The plasma cortisol level was found to be slightly elevated in one patient (G. B.) with untreated myxedema. In two patients with untreated hyperthyroidism, low values were found (D. Y., B. M.). In some of the subjects, determinations were made during the myxedematous or thyrotoxic period and again several months ( 3 to 12 months) following therapy; however, significant changes were not usually observed. The

${ }^{2}$ Turnover rate is defined as the quantity of newly synthesized cortisol added to the miscible pool, presumably by the adrenals, per unit time. The miscible pool is defined as that body of cortisol whose mixing is rapid relative to its turnover. patients with myxedema were treated with desiccated thyroid (90 to $180 \mathrm{mg}$. per day). The patients with hyperthyroidism were treated with propylthiouracil (100 to $300 \mathrm{mg}$. per day), or with methimazole, except for Patient C. M., who received a therapeutic dose of radioactive iodine (4 mc.). D. B. was a normal subject made hyperthyroid by administration of triiodothyronine for four weeks.

All of the subjects with thyrotoxicosis had low levels of 17-ketosteroids in the urine. Normal subject D. B. showed a decline in excretion of 17 ketosteroids after the fourth week of therapy with triiodothyronine. All of the subjects with myxedema had a decreased urine 17-ketosteroids output, and the urine steroid level rose slightly following therapy with thyroid.

In the patients with thyrotoxicosis, the urinary corticoid levels were clearly elevated in D. Y. and B. M. In Patients B. D., C. M., and R. W. (females), the urinary corticoid levels were only slightly above the normal range of 4 to $10 \mathrm{mg}$. per day for females. No elevation of urinary corticoids occurred in the normal subject (D. B.) until the third week of treatment with triiodothyronine. All of the subjects with myxedema had urine corticoid levels below normal, and these returned to normal following therapy with thyroid.

Cortisol (100 to $200 \mathrm{mg}$.) was infused into eight subjects with thyrotoxicosis and five patients with myxedema (Table I). Figure 1 shows the curves of disappearance of cortisol from the plasma of a normal subject, and a patient with hyperthyroidism, and one with myxedema. In the hyperthyroid group, the infused cortisol was removed from the plasma at a greatly accelerated rate, except in the case of Patient V. H. This subject had a moderately enlarged liver and minimally abnormal liver function tests. In all but one of the patients (M. H.) with myxedema, there was a delayed disappearance of cortisol from the plasma. In both groups, following appropriate therapy for the thyroid disorder, the plasma disappearance rates of the infused cortisol returned toward the normal range.

The metabolisms of infused cortisone and corticosterone were found to be altered in the same direction as cortisol (Table I).

The urinary concentration of cortisol was determined in three patients (D. Y., R. W., and 
TABLE I

Plasma and urine steroid levels and biologic half-times of infused steroids

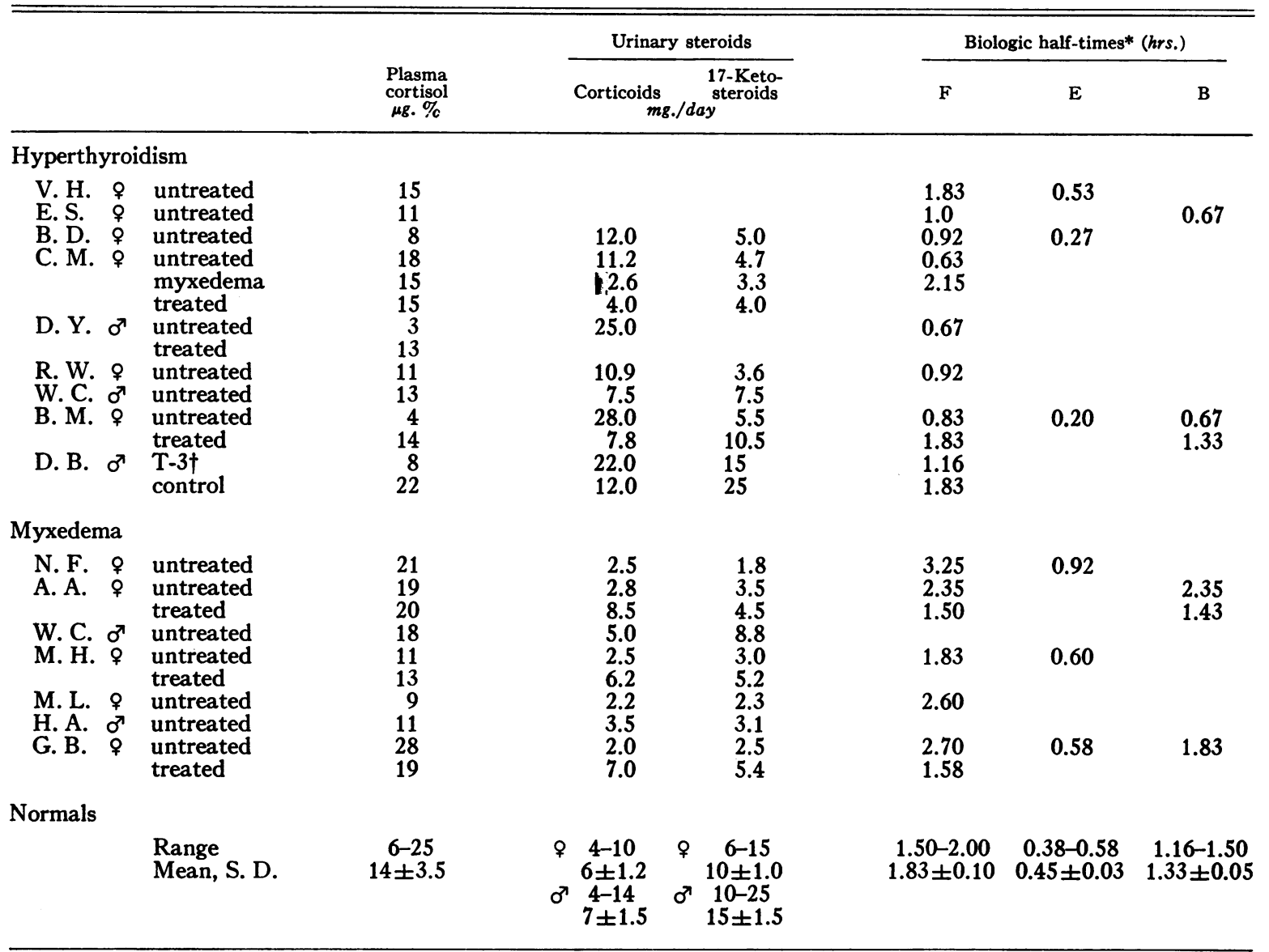

${ }^{*} \mathrm{~F}=$ Cortisol $; \mathrm{E}=$ Cortisone $; \mathrm{B}=$ Corticosterone.

$\dagger \mathrm{T}-3=$ Triiodothyronine.

B. M.) with thyrotoxicosis following the infusion of $200 \mathrm{mg}$. of cortisol. In all subjects, the urine cortisol concentration $(0.8,1.0$, and $2.0 \mathrm{mg}$. per 24 hours) was found to be lower than that obtained in five normal subjects given $200 \mathrm{mg}$. cortisol intravenously ( 2.5 to $3.8 \mathrm{mg}$. per 24 hours). In one patient with myxedema (M. L.), the urine cortisol concentration in the 24 hour urine obtained following the infusion of $200 \mathrm{mg}$. of cortisol was $5.6 \mathrm{mg}$.

Table II shows the data on the miscible pool of cortisol and its turnover rate in the patients with myxedema and thyrotoxicosis. For several of these patients data are also included for the period ( 3 to 12 months) following therapy for the thyroid disorder. In the normal subject (D. B.), the control studies were carried out prior to treatment with triiodothyronine. It may be noted that the fraction of the pool replaced per hour was much increased above normal in the hyperthyroid subjects and less than normal in the myxedema patients. The size of the miscible pool of cortisol in both the hyperthyroid and myxedema patients was not greatly different from that found in normal subjects. Also, in most of the patients studied before and after therapy the pool did not show a striking change in size. In Subject D. B., and Patients D. Y. and B. M. with hyperthyroidism. both the plasma cortisol and miscible pool of cortisol changed significantly in the same direction with a change to the euthyroid state.

In Table II the figures listed for milligrams of cortisol secreted per day may have much less significance than those listed for milligrams of corti- 


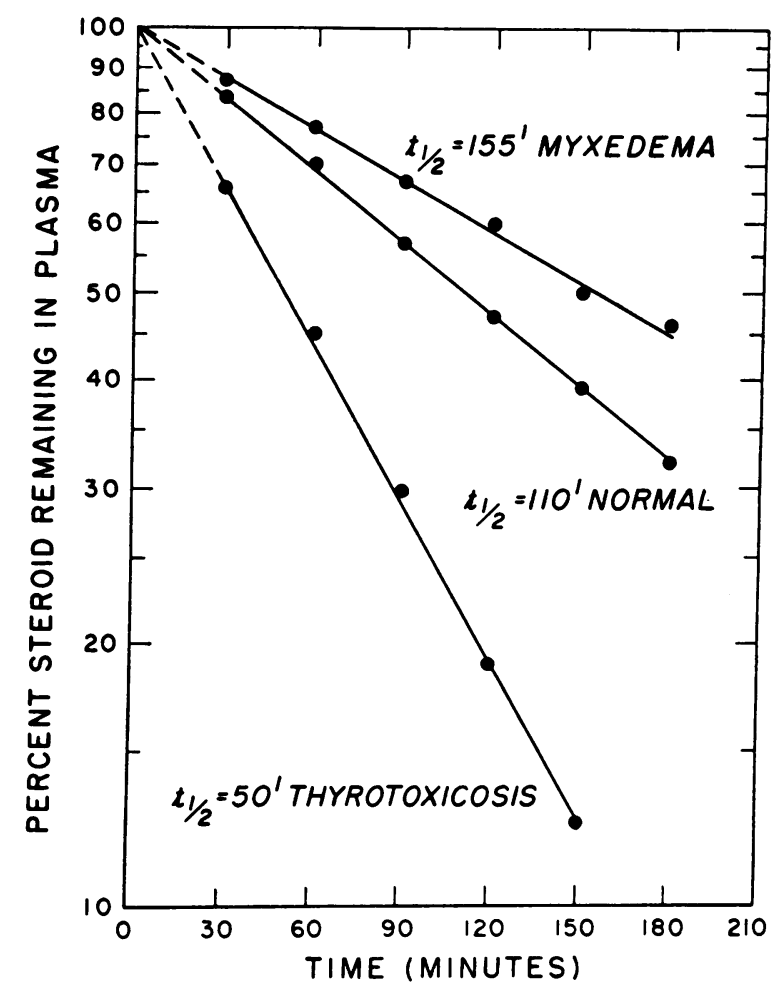

Fig. 1. Disappearance of Cortisol from Plasma Following INTRAVENOUS ADMINISTRATION

Myxedema, Patient M. L. ; thyrotoxicosis, Patient B. M.

sol secreted per hour. This results from the fact that the turnover rate studies cover only a three hour period of the day (9:00 a.m. to noon). These figures are, however, included for the benefit of those who may wish to compare them to the milligrams of urinary corticoids secreted per day in these same patients.

Figure 2 shows the specific activity curves of cortisol-4-C $\mathrm{C}^{14}$ following the infusion of a trace quantity of labeled cortisol into Patient C. M.

\section{DISCUSSION}

The presence of normal plasma cortisol levels in most of the subjects with thyrotoxicosis or myxedema might at first suggest that there is no alteration in adrenal cortical secretion or rate of degradation of cortisol. The concentration of cortisol in the plasma is, however, not always a reliable index of the state of activity of the adrenal cortex since the level of cortisol in the plasma is maintained through the balance of the forces of production and destruction of the hormone.

The 24 hour urinary steroid assay is essentially a measure of metabolites of cortisol and is a reflection of the quantity of cortisol secreted during a day. This procedure represents, however, a rather crude index and suffers the following shortcomings: (a) except for a small fraction of free steroid metabolites, it measures only the fraction of steroid metabolites of cortisol excreted as steroids conjugated as glucuronides $(27) ;(b)$ the steroid glucuronide conjugatęs in the urine normally make up only about 60 per cent of the metabolites of cortisol, but only about one-half of the 60 per cent retain the dihydroxy acetone side chain (27) and thus react with phenylhydrazine in sulfuric acid and ethanol to form the characteristic yellow chromophore absorbing maximally at 410 $\mathrm{m} \mu ;(c)$ a small but variable fraction of the phenylhydrazine reacting material may be nonsteroidal.

Disappearance of cortisol from the plasma is a reflection of the rate of catabolism of the hormone by the liver (27), since only a small quantity is excreted as unaltered cortisol. With but one exception, all of the patients with thyrotoxicosis stud-

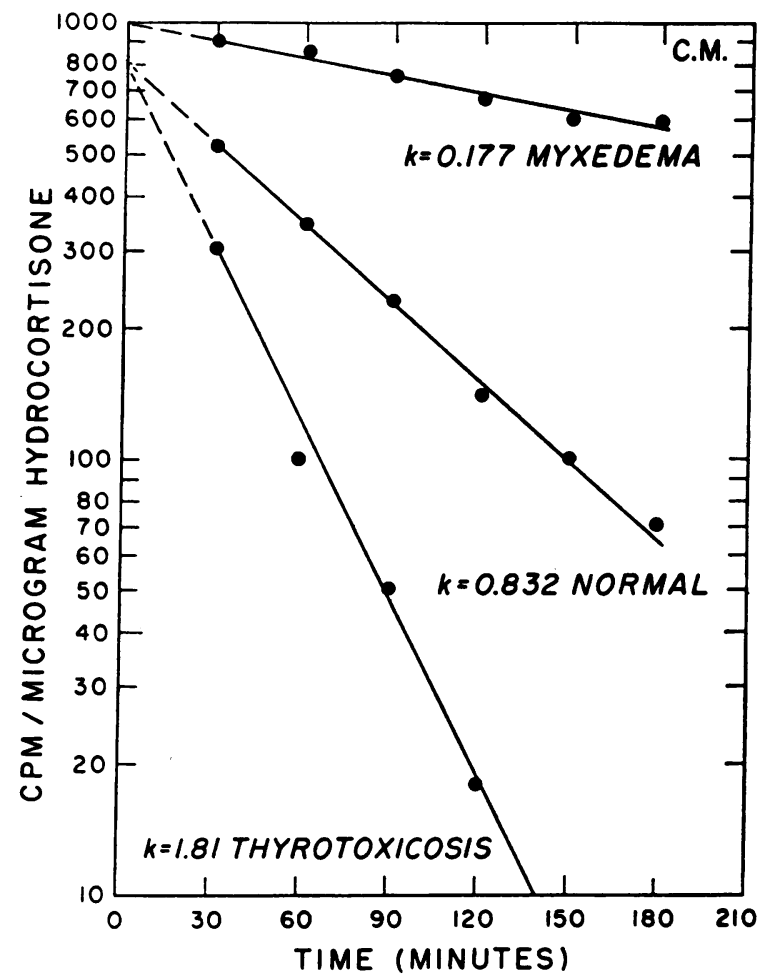

Fig. 2. Plasma Cortisol Specific Activity Following Intravenous Administration of Cortisol-4-C ${ }^{16}$ to Patient C. M. During Periods of Thyrotoxicosis, Mydedema, and the EuthyroId (Normal) State 
TABLE II

Miscible pool and turnover rate of cortisol in thyroid disease

\begin{tabular}{|c|c|c|c|c|c|c|}
\hline & & $\begin{array}{l}\text { Pool } \\
\text { mg. }\end{array}$ & $\begin{array}{l}\mathrm{t}_{1}^{*} \\
h r s .\end{array}$ & $\mathrm{k} \dagger$ & $\begin{array}{l}\text { Turno } \\
m g . / h r .\end{array}$ & $\begin{array}{l}\text { rate } \\
m g . / \text { day }\end{array}$ \\
\hline \multicolumn{7}{|c|}{ Hyperthyroid } \\
\hline $\begin{array}{l}\text { D. B. } \\
\text { D. Y. } \\
\text { C. M. } \\
\text { B. M. } \\
\text { W. C. } \\
\text { R. W. }\end{array}$ & $\begin{array}{l}\text { T-3ł } \\
\text { control } \\
\text { untreated } \\
\text { treated } \\
\text { untreated } \\
\text { myxedema } \\
\text { treated } \\
\text { untreated } \\
\text { treated } \\
\text { untreated } \\
\text { untreated }\end{array}$ & $\begin{array}{l}1.2 \\
2.4 \\
1.0 \\
3.6 \\
1.3 \\
1.2 \\
1.2 \\
0.8 \\
1.5 \\
1.8 \\
-1.6\end{array}$ & $\begin{array}{l}0.38 \\
1.30 \\
0.28 \\
1.07 \\
0.38 \\
3.92 \\
0.83 \\
0.18 \\
0.89 \\
0.67 \\
0.61\end{array}$ & $\begin{array}{l}1.82 \\
0.51 \\
3.90 \\
0.65 \\
1.82 \\
0.18 \\
0.83 \\
5.75 \\
0.72 \\
1.04 \\
1.14\end{array}$ & $\begin{array}{l}2.26 \\
1.22 \\
3.90 \\
1.30 \\
2.41 \\
0.22 \\
1.02 \\
4.60 \\
1.08 \\
1.91 \\
1.83\end{array}$ & $\begin{array}{c}55 \\
29 \\
94 \\
31 \\
58 \\
5.3 \\
24 \\
110 \\
26 \\
46 \\
44\end{array}$ \\
\hline \multicolumn{7}{|c|}{ Myxedema } \\
\hline $\begin{array}{l}\text { M. H. } \\
\text { H. A. } \\
\text { A. A. } \\
\text { G. B. } \\
\text { M. L. } \\
\text { W. C. }\end{array}$ & $\begin{array}{l}\text { untreated } \\
\text { treated } \\
\text { untreated } \\
\text { treated } \\
\text { untreated } \\
\text { treated } \\
\text { untreated } \\
\text { treated } \\
\text { untreated } \\
\text { untreated }\end{array}$ & $\begin{array}{l}2.0 \\
1.4 \\
1.1 \\
3.3 \\
0.8 \\
1.3 \\
2.4 \\
2.0 \\
1.1 \\
2.2\end{array}$ & $\begin{array}{l}9.64 \\
1.05 \\
2.08 \\
1.77 \\
2.33 \\
0.55 \\
4.60 \\
1.10 \\
2.64 \\
2.75\end{array}$ & $\begin{array}{l}0.07 \\
0.66 \\
0.33 \\
0.40 \\
0.29 \\
1.26 \\
0.15 \\
0.63 \\
0.26 \\
0.25\end{array}$ & $\begin{array}{l}0.15 \\
0.94 \\
0.37 \\
1.30 \\
0.23 \\
1.64 \\
0.36 \\
1.25 \\
0.29 \\
0.55\end{array}$ & $\begin{array}{c}3.5 \\
23 \\
8.8 \\
31 \\
4.5 \\
39 \\
8.6 \\
30 \\
7.0 \\
14\end{array}$ \\
\hline & $\begin{array}{l}\text { Range } \\
\text { Mean, S. D. }\end{array}$ & $\begin{array}{c}1.1-2.4 \\
1.7 \pm 0.2\end{array}$ & $\begin{array}{c}1.0-2.3 \\
1.4 \pm 0.2\end{array}$ & $\begin{array}{c}0.3-0.7 \\
0.5 \pm 0.1\end{array}$ & $\begin{array}{c}0.7-1.2 \\
0.85 \pm 0.08\end{array}$ & $\begin{array}{c}17-29 \\
20 \pm 1.0\end{array}$ \\
\hline
\end{tabular}

$* t_{1}=$ Time for the specific activity of plasma cortisol to be reduced by 50 per cent.

$\dagger \mathrm{k}=$ Fraction pool replaced per hour.

$\ddagger \mathrm{T}-3=$ Triiodothyronine.

ied showed a very significantly increased plasma clearance (metabolism) of infused cortisol. The patients with myxedema showed a moderately delayed rate of transformation of infused cortisol.

The above observations have previously been made by Levin and Daughaday (20) and recently confirmed by Di Raimondo, Sagan, Perloff, and Forsham (34).

The increased metabolic transformation of cortisol in thyrotoxicosis is not a unique feature of the metabolism of cortisol since the metabolism of other compounds, viz., cholesterol (35), may be similarly altered by an excess of thyroxine. The specific nature of the defect in the capacity of the liver to metabolize cortisol in thyrotoxicosis has not been elucidated; however, there may be an increase in level of the enzymes or co-enzymes in the liver required for the biotransformation of cortisol and many other steroids. ${ }^{3}$ The concentra-

${ }^{3}$ Crude liver homogenates from rats made thyrotoxic with thyroxine produce a twofold increase in the rate of degradation of cortisol when compared to liver homogenates from normal rats (36). tion of a number of oxidative enzymes is increased in the liver and other tissues of animals following the administration of thyroid, and thyroidectomy is usually followed by a decreased level of these same enzymes (37). The data obtained on the rate of metabolism of other steroids (cortisone, corticosterone) infused into patients with thyrotoxicosis suggests that there may be an increased level of many of the enzymes involved in the metabolic transformations of steroids (38).

With the aid of cortisol-4-C ${ }^{14}$ and utilization of conventional tracer techniques to study the miscible pool and turnover rate of cortisol, it has been possible to show that in patients with myxedema, the rate of synthesis of cortisol by the adrenals was decreased in the presence of a normal miscible pool. In thyrotoxicosis the turnover rate studies showed that the adrenals were producing an increased amount of cortisol in the presence of a normal miscible pool.

In thyrotoxicosis the increased production of cortisol in the presence of eucorticism was in many 
cases reflected by an increase in the concentration of cortisol metabolites in the urine. Patient W. C., however, had a normal urine corticoid level, yet the calculated value for daily cortisol production was about twice normal. Also, cortisol turnover was increased approximately twofold in Patients C. M. and R. W.; however, the urinary corticoid level was only slightly above normal. An explanation for this apparent discrepancy may be related to the unreliability of the urine corticoid assay as discussed previously. ${ }^{4}$ Bradlow, Hellman, Zumoff, and Gallagher (39) have recently published data showing that the level of thyroid function alters the type of urinary metabolites from both endogenous and exogenously administered androgens.

The findings reported in this paper may be explained on the basis of a single primary defect, i.e., alteration in rate of enzymatic transformation of the circulating cortisol by the liver. The liver may thus influence indirectly the production of cortisol through its control of one of the humerol regulators (plasma cortisol level) controlling secretion of corticotropin. In thyroid disease, as in liver disease, it may be the functional capacity of the liver to metabolize cortisol and not the requirements of the tissue cells that dictate the control of the pituitary adrenal cortical system.

An alternate hypothesis might be that thyroid hormone acts directly on the pituitary or adrenal to control cortisol secretion. In animals it has been found that an intact pituitary is necessary to obtain adrenal cortical hypertrophy following thyroid administration $(40,41)$. This observation in animals would also seem to rule out the possibility that the excess circulating thyroid hor-

\footnotetext{
4 Following the injection of cortisol-4-C $\mathrm{C}^{16}$ to patients with thyrotoxicosis and myxedema, an average of 77 per cent of the radioactivity was present in the first 24 hour urine collection. Glucuronidase hydrolysis and dichloromethane extraction of these same urines resulted in an average recovery of 45 per cent of the administered radioactivity. These data are similar to the data reported for normals (27), and demonstrate that in thyroid disease there is no alteration in either the total quantity of the cortisol metabolites excreted or that fraction conjugated as glucuronides. It is possible, as suggested by the studies of Levin and Daughaday (20), that in thyrotoxicosis there is a more extensive degradation of the steroid molecule; viz., a preferential increased reduction of the C-20 ketone group of cortisol to form a larger fraction of nonphenylhydrazine-reacting urinary steroid metabolites.
}

mone acts directly on the adrenal cortex independent of the pituitary (or circulating corticotropin) to increase cortisol secretion. If the thyroid hormone were to act directly on the pituitary or adrenal, it would be necessary to invoke more than a single defect since the liver is clearly involved and must be included in any explanation in order to account for the normal plasma cortisol level.

A renal mechanism probably need not be introduced to explain the reported observations since only a small fraction of the secreted cortisol is lost via the kidneys [50 to $150 \mu \mathrm{g}$. per day (42)]. Also, the data on the concentrations of cortisol in the urine after infusion of cortisol to normals and patients with thyroid disease demonstrate that very little of the circulating cortisol is disposed of by the kidneys.

In both the thyrotoxic and myxedematous patients, there was a low urinary output of neutral 17-ketosteroids. In the patients with thyrotoxicosis, the low 17 -ketosteroids are probably not the result of a decreased conversion of 17-hydroxy steroids such as cortisol or its metabolites to 17ketosteroids, since normally only a small fraction (about 10 per cent) of the cortisol is metabolized to 17-ketosteroids. Also, these patients actually had a greater quantity of cortisol available for transformation to 17 -ketosteroids. The only explanation that is apparent at this time without additional data is that in thyrotoxicosis, the adrenal cortex secretes cortisol in preference to the androgens (17-ketosteroids).

The various clinical implications of these studies deserve some comment. The data would indicate that patients with myxedema have a relative adrenal insufficiency, especially as regards secretion of cortisol. Under normal or basal conditions, such patients experience no difficulty because they metabolize the secreted cortisol at a decreased rate. By virtue of a normally intact pituitary-adrenal cortical system, the patient with myxedema is not subjected to a plethora of cortisol. Under conditions of stress, the adrenals of these patients may be able to effect an adequate response, which, however, need only be subnormal since any additional cortisol secreted will remain for a longer time in the miscible pool. It is well known that administration of thyroxine to patients with Addison's disease may precipitate adrenal crisis (24, 
25), and it might be anticipated that if a patient with severe myxedema were treated too vigorously with thyroid, adrenal cortical insufficiency could be induced.

The thyrotoxic individual is capable of manufacturing each day a quantity of cortisol that in a normal subject would quickly induce a state of hypercorticism. It might be postulated that if the hyperthyroid state were severe enough, as in a thyroid crisis, the rate of transformation of secreted cortisol might exceed the capacity of the adrenal to synthesize cortisol, and thus adrenal insufficiency might develop in the presence of an overproduction of cortisol. [In normal subjects, the adrenal appears to be capable of synthesizing 150 to $200 \mathrm{mg}$. of cortisol per day with maximal corticotropin stimulation (33).] Thus, such patients might be benefitted by exogenously administered cortisol and indeed this has been advocated as an important therapeutic adjunct to the treatment of the thyroid crisis (43).

\section{SUMMARY}

Plasma cortisol levels were normal in most patients with myxedema or thyrotoxicosis. Urine 17-ketosteroids were low in both myxedema and thyrotoxicosis. Urine corticoids were low in myxedema, and normal or moderately elevated in thyrotoxicosis. The urine corticoids returned to normal more promptly than the 17 -ketosteroids following treatment of the thyroid disorder. Infused steroids were found to disappear from the plasma at an increased rate in thyrotoxicosis, and at a decreased rate in myxedema. Appropriate therapy for the thyroid disease returned the metabolism of the infused steroids to normal. The rate of synthesis of cortisol was reduced in myxedema and increased in thyrotoxicosis, and these alterations in the rate of secretion of cortisol were not associated with a significant change in the size of the miscible pool. Institution of the euthyroid state in these patients returned adrenal cortisol production to normal.

It is suggested from these data that there is a homeostatic mechanism mediated through the liver-pituitary-adrenals which results in a decreased synthesis of cortisol in patients with myxedema in whom the rate of removal of cortisol by the liver is impaired, and an increased synthesis of cortisol in patients with thyrotoxicosis in whom the rate of removal of cortisol by the liver is accelerated.

\section{ACKNOWLEDGMENT}

Dr. Jacob Robbins of the National Institute of Arthritis and Metabolic Diseases made available several of the patients with thyroid disease used in this study.

\section{REFERENCES}

1. Money, W. L. The interrelation of the thyroid and the adrenals in The Thyroid, Brookhaven Symposium in Biology, No. 7. Upton, Brookhaven National Laboratory, 1954, p. 137.

2. Means, J. The Thyroid and Its Diseases, 2nd ed. Philadelphia, J. B. Lippincott Co., 1948, p. 249.

3. Marine, D. Remarks on the pathogenesis of Graves' disease. Amer. J. med. Sci. 1930, 180, 767.

4. LeCompte, P. M. Width of adrenal cortex in lymphatic leukemia, lymphosarcoma, and hyperthyroidism. J. clin. Endocr. 1949, 9, 158.

5. Holst, J. Pathologische Anatomie der Organe ausser der Schilddrüse bei der Basedow'schen Krankheit. Internationale Kropfkonferenz, Zweite, Bern, 1933, Verhandlungsbericht. Bern, H. Huber, 1935, p. 62.

6. Berkheiser, S. W. Adult hypothyroidism: Report of an advanced case with autopsy study. J. clin. Endocr. 1955, 15, 44.

7. Tepperman, J., Engel, F. L., and Long, C. N. H. A review of adrenal cortical hypertrophy. Endocrinology 1943, 32, 373.

8. Hertz, R., Tullner, W. W., Schricker, J. A., Dhyse, F. G., and Hallman, L. F. Studies on amphenone and related compounds. Recent Progr. Hormone Res. 1955, 11, 119.

9. Daughaday, W. H., Jaffe, H., and Williams, R. H. Adrenal cortical hormone excretion in endocrine and non-endocrine disease as measured by chemical assay. J. clin. Endocr. 1948, 8, 244.

10. Shadaksharappa, K., Calloway, N. O., Kyle, R. H., and Keeton, R. W. Excretion of steroidal substances by the adrenal cortex in various diseases. J. clin. Endocr. 1951, 11, 1383.

11. Hernberg, C. A., and Lamberg, B. A. Adrenal function and thyrotoxicosis. Acta. endocr. (Kbh.) $1955,18,41$.

12. Gabrilove, J. L., and Soffer, L. J. Effect of thyrotropin on adrenocortical function. J. clin. Endocr. 1955, 15, 585.

13. Fraser, R. W., Forbes, A. P., Albright, F., Sulkowitch, H., and Reifenstein, E. C., Jr. Colorimetric assay of 17-ketosteroids in urine. A survey of the use of this test in endocrine investigation, diagnosis, and therapy. J. clin. Endocr. 1941, 1, 234.

14. Engstrom, W. W., and Mason, H. L. The excretion of 17-ketosteroids in patients with hyperthyroidism and myxedema. J. clin. Endocr. 1944, 4, 517. 
15. Statland, H., and Lerman, J. Function of the adrenal cortex in myxedema, with some observations on pituitary function. J. clin. Endocr. 1950, 10, 1401.

16. Kenigsberg, S., and McGavack, T. H. The excretion of 17 -ketosteroids. II. Values in several endocrine disturbances. J. clin. Endocr. 1952, 12, 1551.

17. Beierwaltes, W. H., and Bishop, R. C. 17-Ketosteroid and pituitary follicle-stimulating hormone excretion in myxedema, before and during treatment with thyroxine. J. clin. Endocr. 1954, 14, 928.

18. Goldenberg, I. S., Lutwak, L., Rosenbaum, P. J., and Hayes, M. A. Thyroid-adrenocortical metabolic interrelations. J. clin. Endocr. 1955, 15, 227.

19. Perkoff, G. T., Sandberg, A. A., Nelson, D. H., and Tyler, F. H. Clinical usefulness of determination of circulating 17-hydroxycorticosteroid levels. Arch. intern. Med. 1954, 93, 1.

20. Levin, M. E., and Daughaday, W. H. The influence of the thyroid on adrenocortical function. J. clin. Endocr. 1955, 15, 1499.

21. Wallace, E. Z., Christy, N. P., and Jailer, J. W. Clinical application of the simplified Silber-Porter method for determining plasma 17-hydroxycorticosteroids. J. clin. Endocr. 1955, 15, 1073.

22. Zondek, $\mathrm{H}$. The Diseases of the Endocrine Glands, 3rd ed. London, Edward, Arnold and Company, 1935.

23. Zwemer, R. L. An experimental study of the adrenal cortex. II. Prolongation of life after complete epinephrectomy. Amer. J. Physiol. 1927, 79, 658.

24. Lerman, J., and Stebbins, H. D. The pituitary type of myxedema: Further observations. J. Amer. med. Ass. 1942, 119, 391.

25. Means, J. H., Hertz, S., and Lerman, J. The pituitary type of myxedema or Simmond's disease masquerading as myxedema. Trans. Ass. Amer. Phycns. 1940, 55, 32.

26. Paull, A. M., and Phillips, R. W. Primary myxedema with secondary adrenocortical failure. $\mathrm{J}$. clin. Endocr. 1954, 14, 554.

27. Peterson, R. E., Wyngaarden, J. B., Guerra, S. L., Brodie, B. B., and Bunim, J. J. The physiological disposition and metabolic fate of hydrocortisone in man. J. clin. Invest. 1955, 34, 1779.

28. Peterson, R. E., Karrer, A., and Guerra, S. L. Evaluation of the Silber-Porter procedure for determination of plasma hydrocortisone. Analyt. Chem. 1957, 29, 144.
29. Silber, R. H., and Porter, C. C. The determination of 17,21-dihydroxy-20-ketosteroids in urine and plasma. J. biol. Chem. 1954, 210, 923.

30. Holtorff, A. F., and Koch, F. C. The colorimetric estimation of 17-ketosteroids and their application to urine extracts. J. biol. Chem. 1940, 135, 377.

31. Peterson, R. E., Pierce, C. E., Wyngaarden, J. B., Bunim, J. J., and Brodie, B. B. The physiological disposition and metabolic fate of cortisone in man. J. clin. Invest. 1957, 36, 1301.

32. Peterson, R. E. The identification of corticosterone in human plasma and its assay by isotope dilution. J. biol. Chem. 1957, 225, 25.

33. Peterson, R. E., and Wyngaarden, J. B. The miscible pool and turnover rate of hydrocortisone in man. J. clin. Invest. 1956, 35, 552.

34. Di Raimondo, V., Sagan, L., Perloff, P., and Forsham, P. H. Studies of adrenocortical activity in hypo- and hyperthyroid states in man. Personal communication.

35. Rosenman, R. H., Byers, S. O., and Friedman, M. The mechanism responsible for the altered blood cholesterol content in deranged thyroid states. J. clin. Endocr. 1952, 12, 1287.

36. McGuire, J., and Tomkins, G. Personal communication.

37. Lardy, H. Effect of thyroid hormones on enzyme systems in The Thyroid, Brookhaven Symposium in Biology, No. 7. Upton, Brookhaven National Laboratory, 1954, p. 90.

38. Tomkins, G. M. Enzymatic mechanisms of hormone metabolism. I. Oxidation-reduction of the steroid nucleus. Recent Progr. Hormone Res. 1956, 12, 125.

39. Bradlow, H. L., Hellman, L., Zumoff, B., and Gallagher, T. F. Interaction of hormonal effects: Influence of triiodothyronine on androgen metabolism. Science 1956, 124, 1206.

40. Smith, P. E., Greenwood, C. F., and Foster, G. L. A comparison in normal, thyroidectomized, and hypophysectomized rats of the effects upon metabolism and growth resulting from daily injections of small amounts of thyroid extract. Amer. J. Path. 1927, 3, 669.

41. Feldman, J. D. Endocrine control of the adrenal gland. Anat. Rec. 1951, 109, 41.

42. Peterson, R. E. Unpublished data.

43. Rawson, R. W., and Rall, J. E. Diseases of the thyroid in Duncan's Diseases of Metabolism, 3rd ed. Philadelphia, W. B. Saunders, 1952, p. 1007. 